\title{
LIGHTNING INDUCED VOLTAGES ON POWER DISTRIBUTION LINES -OBSERVATION RESULTS AT FUKUI STEAM POWER SATATION-
}

\section{S. Yokoyama} Central Research Institute of Electric Power Industry
Tokyo 201 JAPAN

\begin{abstract}
Waveforms of induced voltage from lightning strokes to a tall stack of the power plant have been measured simultaneously with the current waveforms of lightning stroke to the stack since December 1980. This paper shows the lightning stroke current waveforms and the lightning induced voltage waveforms over a 9 year period from December 1980 through March 1988.
\end{abstract}

\section{Introduction}

Lightning voltage induced by nearby strokes is one of the causes of major overvoltages which threaten insulation of power distribution lines. A number of theoretical investigations and measurements have been conducted on such lightning induced voltages $[1-5]$.

In spite of these researches, there have been very few observations which are reinforced by additional data such as lightning photographs and lightning stroke current measurements directed to nearby strokes to a distribution line.Therefore the author began to conduct simultaneous measurements of the induced voltage waveforms, still camera photography and lightning current waveforms.

This paper gives observation results which were obtained from December 1980 through March 1988 in order to clarify the characteristics of lightning induced voltages.

2. observation Method

\section{2-1 Location of the experimental distribution line}

An experimental

distribution line for measuring induced voltages was constructed on a stretch of level ground along the seashore at the Fukui steam power station (Hokuriku Elctric Power Company). Figure 1 shows the location of the power station, and Figure 2, a layout of the tall stack and the distribution line. The line measures a total of $820 \mathrm{~m}$ from the No. 1 pole to the No. 17 pole, with an interval of about $50 \mathrm{~m}$ between each pole.

This line was constructed specifically for the measurement of

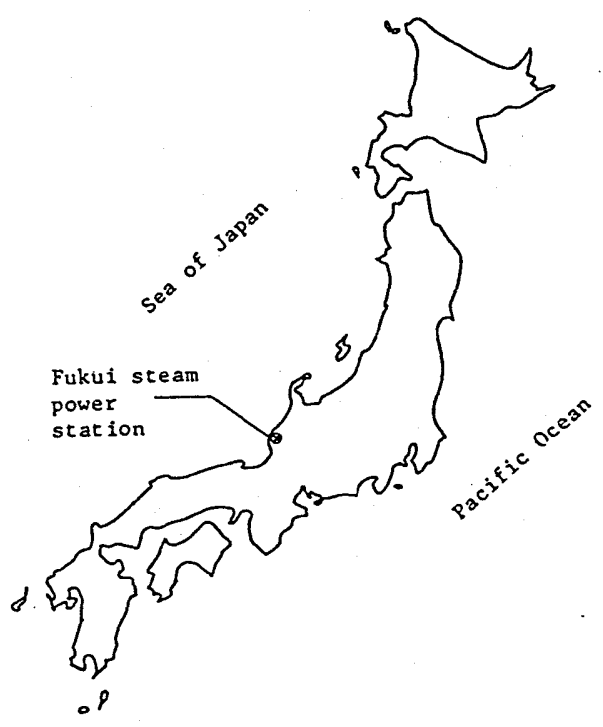

Fig.1 Location of Fukui steam power station 
Sea of Japan

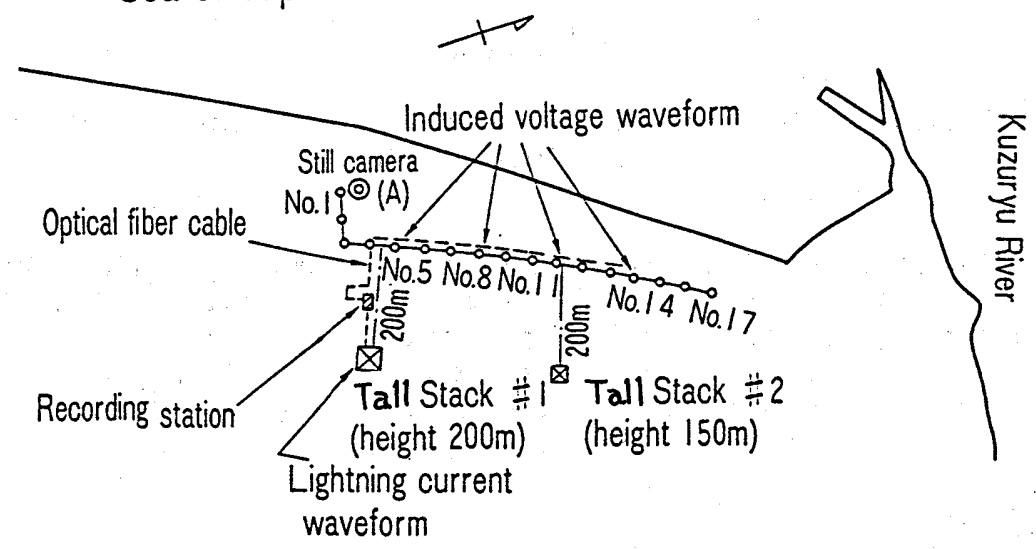

Fig. 2 Layout of distribution 1 ine and measuring instruments

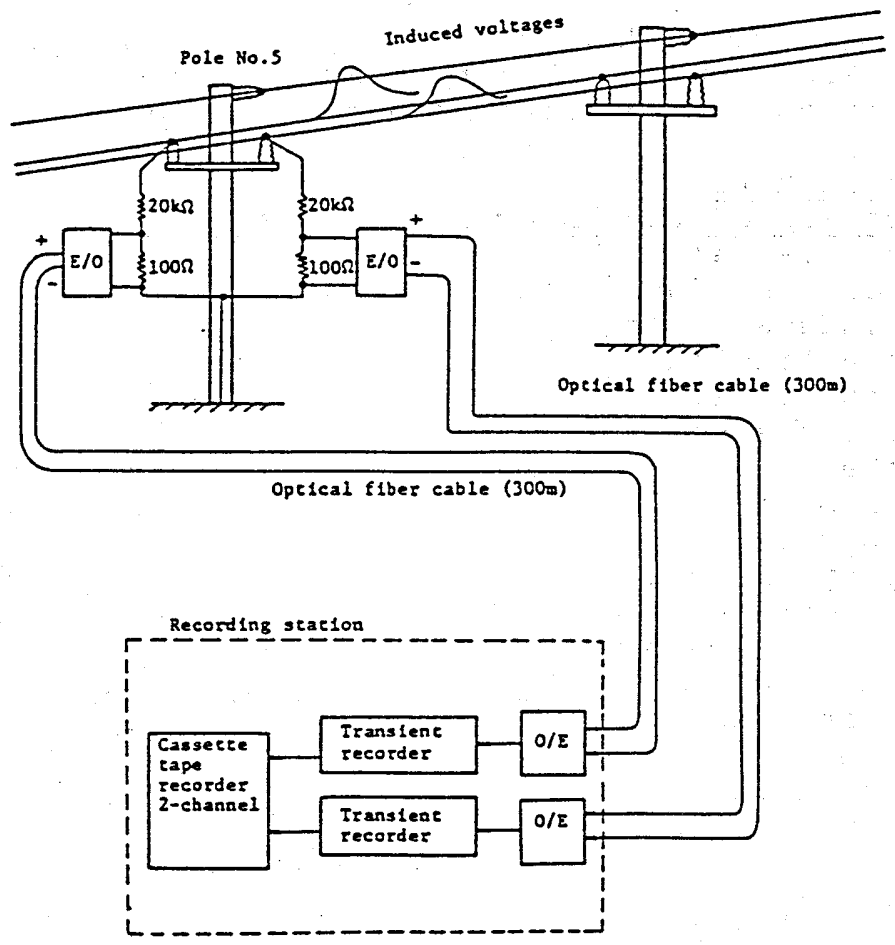

Fig. 3 Automatic observation system for lighting induced voltages 
induced voltages and was not energized with ac voltage. the shortest distance to the tall stack (height, $200 \mathrm{~m}$ ) at the power station where the lightning current waveforms were measured is $200 \mathrm{~m}$.

2-2 Items of observation

In order to obtain the distribution of lightning induced voltages along the distribution line, instruments for measuring the induced voltages were installed at 4 points.

Items of observations were as follows.

(a) Lightning stroke current : Tall stack \#1

(b) Induced voltage: pole No.5, No. 8, No.11, No. 14

2-3 Induced voltage measuring unit

This device,designed as shown in Fig.3, performs the automatic measurement of the voltages induced on the distribution line. Induced voltage is reduced to $1 / 200$ by $a$ 20 kiloohm resistive divider and enters an electricity-light conversion (E/O) device and is sent out over an optical fiber cable. After passing over several hundred meters of optical cable, the signal is received in the measuring room, where it is converted into voltage. This signal then subjects to analog-digital conversion and is recorded temporarily, following the completion of which it is transferred to a cassette tape recorder and stored permanently.

3. Observation Results

A total of 90 voltage waveforms were observed from December 1980 through March 1988. Recording of lightning current waveforms coincided in 32 cases.

Examples of the waveforms of lightning stroke currents at the tall stack \#1 and induced voltages on the distribution line are shown in Fig. 4 .

3-1 Combination of polarities for waveforms of lightning

induced voltage and lightning stroke current

(a) Positive lightning induced voltage and negative lightning stroke current: 26 cases

(b) Negative lightning induced voltage and positive lightning stroke current: 6 cases

3-2 Distribution of lightning induced voltages along distribution line length

In such a case that a lightning flash hit the tall stack \#1 (Fig.2), the peak values of the induced voltage: on poles No. 8 , No.11, and No.14 were compared with that of pole No.5 to which the tall stack of the power plant is closest.

The proportions are plotted in fig. 5 which clarifies that the peak value of the induced voltage decreases with increasing distance from the lightning striking point.

From the above results we may pay attention only to an adjacent section to the closest point from a lightning stroke in relation to the lightning protection of high voltage overhead distribution system.

4. Numerical Analysis of Induced Voltages

With the lightning flash position (at point $200 \mathrm{~m}$ from the distribution line) and the lightning current waveform identified, an attempt was made to determine by numerical analysis the induced voltage generated in the line for case 81-02.

Calculations were carried out by dividing the length of the Iine and time into finite portions and solving the partial differential equation. The method of calculation is developed by 
74 Yokoyama: Lightning Induced Voltages on Power Distribution

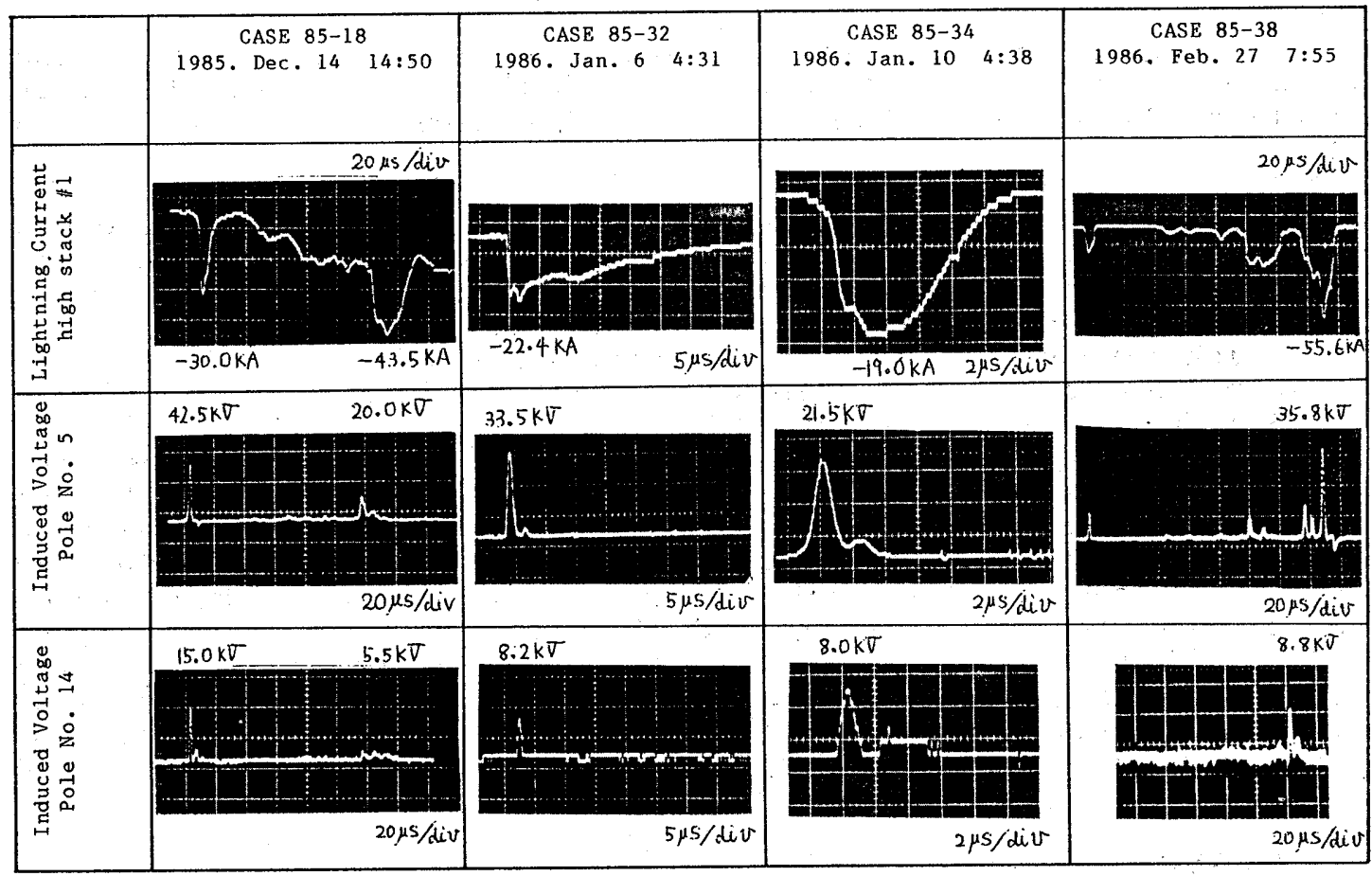

\begin{tabular}{|c|c|c|c|c|}
\hline & CASE $86-03$ & CASE $86-05$ & CAST 86-06 & CASE $87-07$ \\
\hline & 1986. Jul. 9 12:35 & 1987. Jan. $19 \quad 21: 59$ & 1987. Feb. $25 \quad 7: 30$ & 1987. Feb. $28 \quad 17: 31$ \\
\hline 晜 & & $26.0 \mathrm{kA} \quad 36.9 \mathrm{kA}$ & & $76.0 \times A$ \\
\hline 곤 & $-61.5 \mathrm{kA} \quad 5 \mu \mathrm{s} / 2 \mathrm{iv}$ & $20 \mu \mathrm{s} / \mathrm{div}$ & $5 \mu \mathrm{s} / \mathrm{div}$ & $20 \mu \mathrm{s} / \mathrm{div}$ \\
\hline 点 & $106.0 \mathrm{~kJ}$ & $20 \mu \mathrm{s} / \mathrm{div}$ & $+19.6 \mathrm{~kJ}$ & div \\
\hline 点 & $x^{2}+x^{2}$ & & $5 \mu \mathrm{s} / \mathrm{div}$ & $-57.0 \mathrm{~kJ}$ \\
\hline 离 & $45.7 \mathrm{kV}$ & $20 \mu \mathrm{s} / \mathrm{div}$ & $8.4 \mathrm{kV}$ & \\
\hline & $5 \mu \mathrm{s} / \mathrm{div}$ & $\nabla-7.5 \mathrm{k \sigma}$ & div & \\
\hline
\end{tabular}

* Waveform was affected in some degree by surge arrester discharge.

Fig. 4 Waveforms of lightning induced voltages and simultaneous lightning stroke currents 


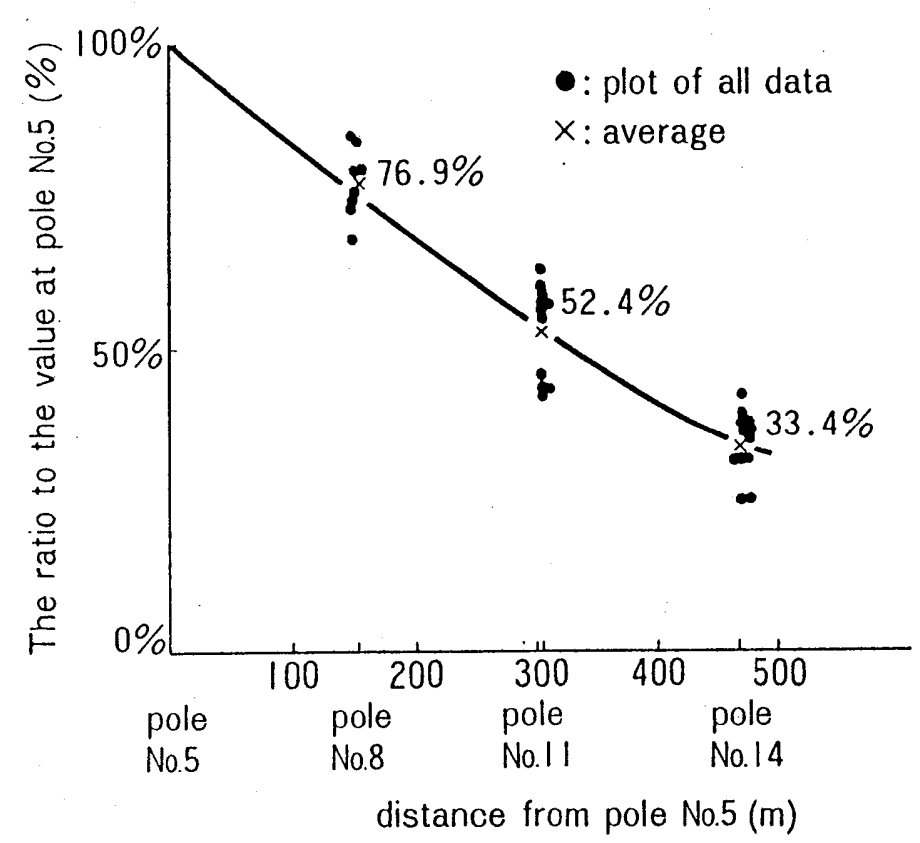

Fig.5 Distribution of lightning induced voltages along distribution line length

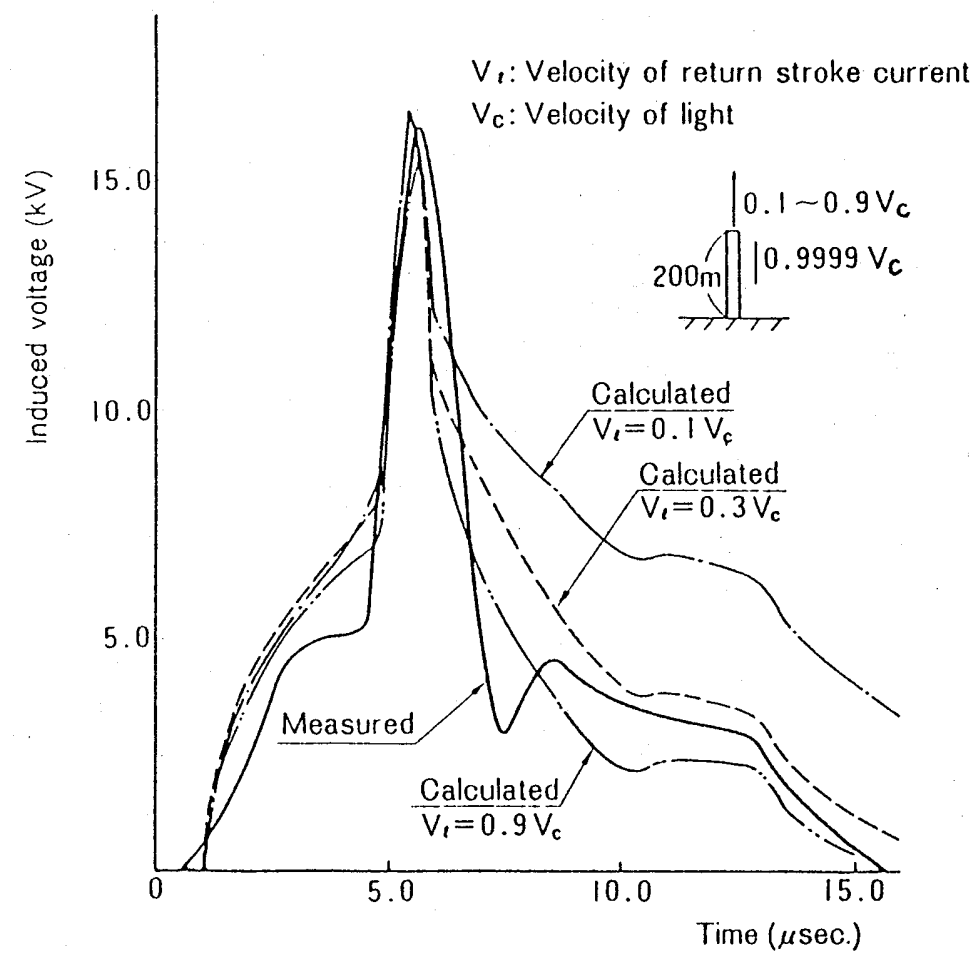

Fig. 6 Comparison between calculated value and measured value of induced voltage 
the author in an earlier paper [6]. The calculated values show close agreement with the measured values for both the peak value and the waveform(Fig.6). In contrast with previous studies in which the two parameters that exert the greatest influence on the induced voltage generated, the lightning current waveform and the flash position, were assumed, the numerical analysis performed in this study applies data collected from measurements, making this investigation highly reliable for comparing the theory with the measurement.

\section{Conclusions}

An experimental distribution line and instruments for measuring the induced voltage were set up at the Hokuriku Electric Power Company, Fukui steam power station, where lightning current waveform measurements and still camera photography had been conducted. Automatic measurements began in December 1980, and a large number of data were collected on winter lightning through March 1988. The major results obtained are summarized below.

(a) The polarity of lightning induced voltage is opposite to that of lightning stroke current.

(b) The lightning induced voltage on the closest point of a distribution line to the lightning flash point is the maximum.

(c) The induced voltage waveforms generated on a distribution line were calculated by means of numerical analysis using the measured lightning current waveforms. The calculated results agree well with the observed induced voltage waveforms.

Aknowledgement

The author wishes to express his gratitude to the staff of the Technical Laboratory of the Hokuriku Electric Power Company Inc. and the Central Research Institute of Electric Power Industry for their support of experiments.

\section{References}

[1] S.Rusck, "Induced Lightning Over-Voltages on Power Transmission Lines with special Reference to the Over-Voltage Protection of Low Voltage Networks". Trans. Royal Institute of Technology, Stockholm, Sweden, 1958.

[2] P.Chowdhuri and E.T.B. Gross, "Voltage Surges Induced on Overhead Lines by Lightning Strokes", Proc. IEE, 114, (12), pp. 1899-1907, 1967 .

[3] A.J.Eriksson and D.V.Meal, "Lightning Performance and Overvoltage Surge studies on a Rural Distribution Line", Proc. IEE. Vol. 129, Pt. C, No.2, pp. 59-69, 1982 .

[4] M.J.Master and M.A.Uman, "Lightning Induced Voltages on Power Lines: Theory", IEEE Trans., Vol. PAS-103, pp. 2502-2518, 1984 .

[5] A.C.Liew and S.C.Mar, "Extension of the Chowdhuri-Gross Model for Lightning Induced Voltage on overhead Lines", IEEE Trans. on Power Systems, Vol. PWRD-1, pp. 240-247, 1986.

[6] S.Yokoyama, "Calculation of Lightning Induced Voltages on overhead Multiconductor Systems", IEEE.Trans., Vol. PAS-103, pp. $100-108,1984$. 